\title{
ESTUDOS DAS ÁREAS DE PROTEÇÃO AMBIENTAL E TOMBAMENTO: Comparação das APAs Corumbataí / Botucatu / Tejupá e Cajamar / Cabreúva / Jundiaí
}

HELENA NAPOLEON DEGREAS*

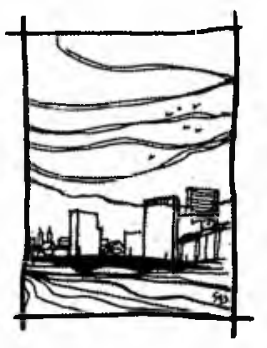

O presente trabalho é parte integrante da dissertação de mestrado desenvolvida por nós e denominada "Paisagem e Proteção Ambiental - do conceito ao desenho" e que foi orientada pelos professores: Dra. Miranda Martinelli Magnoli e Dr. Silvio Soares Macedo.

Interessa-nos aqui conhecer, entender e discutir, dentro do possível, a qualidade de algumas das formas e instrumentos legais de intervenção humana sobre o suporte físico e seus impactos sobre o meio ambiente e paisagem.

\section{DESENVOLVIMENTO HISTÓRICO DA TUTELA NĀO PENAL DA ECOLOGIA - SUMÁRIO}

A dramaticidade do problema ecológico no presente momento e os compromissos muitas vezes assaz rigorosos assumidos pelos Estados no plano internacional determinam intensas atividades de revisão dos ordenamentos internos, em manifesto desacordo com os parâmetros legislativos e com a praxe tradicional. Antes que se verifique o progresso científico e tecnológico, o desenvolvimento demográfico e industrial, o recurso intensivo a fontes de energia diversas daquelas originariamente retiradas do mundo vegetal e animal, antes que os hidrocarburantes, os anticriptógamos e os fertilizantes alterassem a imagem da natureza, que parecia eterna, o equilíbrio não iria constituir-se em bem digno de tutela jurídico."1

"Não é que faltassem os fenômenos de degradação ambiental. Acontece. porém. que toda aquela gama de fenômenos peculiares que. embora diversos quantitativa e qualitativamente dos atuais. são hoje considerados diretamente lesivos do ambiente ecológico em que vive e opera o homem (do ponto de vista coletivo), descritos e interpretados de maneira diversa. O que se encontra como ponto de partida. em todas as experiências internas, é uma tutela meramente civilística. A primeira reação dos ordenamentos contra a poluição foi no plano histórico. a 
ação da natureza meramente civil contra as "emissões" prejudiciais, quer quando o bem danificado fosse objeto de um direito patrimonial alheio."=

A degradação não era considerada como um efeito danoso para a coletividade, mas apenas como um fator de incômodo para os proprietários de terras vinhas ofendidas diretamente pela atividade de uma fonte poluidora bem individualizada.

Pode-se dizer que os bens e valores eram, até a primeira metade do século, "egoisticamente individuais" resultando num descaso ao ambiente natural visto enquanto bem social coletivo.

Assim o direito da ecologia não poderia existir, pois não encontrava respaldo em princípios contraditórios com aqueles que norteavam. Somente a partir da revisão do papel do homem no contexto social é que ocorreram modificações ecológicas, no campo penal, transformando a perspectiva coletivista e individualista no ordenamento jurídico para dar lugar a uma imagem social do homem.

Apesar da lentidão, algo mudou com o decorrer dos anos. "Gradativamente foram acrescidas novas formas específicas de tutela. Por essa via, ao lado da sistemática civilística tradicional, os elementos ambientais encontravam ulterior garantia em disposições de caráter sanitário, de tutela da segurança ou de higiene do trabalho, ou então em matéria de indústrias insalubres e perigosas. As medidas administrativas assim adotadas apresentavam-se bastante semelhantes em sua substância. embora encontrassem agasalho em fontes normativas diversas." ${ }^{3}$

"Muito embora o conjunto de normas mencionadas não realize uma completa mas setorial defesa da poluição, impõe-se reconhecer que, com ela, mudou a perspectiva do problema com relação aos horizontes privatísticos que confinavam a matéria. $O$ problema deixou as relações de mera vizinhança, para ser transportado em uma moldura publicística que permite a averiguação preventiva do potencial poluidor das descargas industriais e a conseqüente adoção de contramedidas administrativas, quando na fase da instalação de aparelhos perigosos. Torna-se assim generalizada, nas ordenações de civilização amadurecida, a submissão de prévia autorização para o início de atividades industriais de alta taxa poluidora, além da inspeção e do controle sobre o seu funcionamento.

O enriquecimento do setor normativo no que concerne aos bens ambientais, se bem que lacunoso em sua previsão e escassamente funcional em sua aplicação, teve de qualquer modo a vantagem de atrair a atenção sobre eles e de acentuar o alarme social com relação aos fatores determinantes do dano. Desse modo foi-se preparando o terreno para uma nova concepção do valor normativo do ambiente 
humano e dos elementos que o integram. Nasceu, então, progressivamente uma legislação propriamente "ecológica" Ou seja, uma legislação construída segundo contextura peculiar, já que encontra sua principal razão de ser na exigência de assegurar à coletividade um uso equilibrado e razoável dos recursos naturais. Hoje nas ordenações mais evoluídas, o problema ambiental atravessa esse estágio de transição rumo à maturidade... O direito penal assimila o sistema axiológico pelo qual se regem as novas Constituições, garantindo e reconhecendo, ao lado dos valores tradicionais, como aqueles da propriedade e da liberdade econômica, valores novos, como aqueles de capacidade para o trabalho ou do desfrutamento de um ambiente sadio. Nascem, assim, as bases para a criação de um verdadeiro "direito penal social" isto é, de um direito penal que oferece sustento e proteção aos valores do homem que opera em sociedade." 4

Do Direito Penal Social faz parte integrante certamente o Direito Penal Ecológico, pois a ecologia se apresenta como um bem social por excelência; e a garantia de um ambiente puro representa um direito social de todo indivíduo.

\section{ATUAÇĀO DO ESTADO NA QUESTÃO AMBIENTAL - SUMÁRIO}

Grande parte do atual trabalho foi retirado de textos e de depoimentos de autoria do Arq. Kazuo Sakurai Gerente de Planejamento Ambiental das Atividades Sócioeconômicas da CETESB.

"Pode-se considerar que oficialmente a atuação do Estado na questão ambiental teve início no segundo quartel desse século." ${ }^{5}$ Por muito tempo predominou a desproteção total, de sorte que não existiam normas que coibissem a devastação de florestas, o escoramento das terras e nem a ameaça do equilíbrio ecológico. A concepção individualista da propriedade constituía forte barreira à atuação do poder público na proteção do meio ambiente, que necessariamente haveria de importar em limitar aquele direito.

"Com a crescente multiplicação dos problemas de poluição e deterioração ambiental surgiram as primeiras leis e ações de controle da mesma procurando minimizar os efeitos do crescimento econômico sobre o meio ambiente.

Muitas dessas ações resultaram a partir de pressões exercidas por entidades profissionais, ou pela necessidade de se manter o sistema produtivo, muitas vezes ameaçadas pela poluição por ele causada."6

No setor rural, devido à extensão territorial permitir a conquista sucessiva de novas terras, as consequiências de uma agricultura predatória não se fizeram sentir de uma forma tão marcante quanto hoje. 
Assim, foi nas cidades, onde se concentram as atividades econômicas, que se concentram os problemas ambientais delas decorrentes e onde se iniciaram as gestōes para minimizar os conflitos que começaram a se intensificar. No final do século XIX, já tinha sido criado o Serviço Sanitário do Estado de São Paulo e promulgado o Código Sanitário, onde se estabelecia uma classificação das indústrias em incômodas, perigosas e insalubres e se estipulavam ainda, regras com vistas à proteção da saúde pública.

"Na década de 20 algumas ações governamentais procuraram ampliar a atuação pública sobre as questôes ambientais, incluindo medidas relativas à proteção da fauna aquática do estado de São Paulo. No mesmo ato foi criado o Instituto Biológico, com poderes fiscalizadores sobre fungicidas, inseticidas, parasiticidas e produtos congêneres, assim como dos medicamentos ou profiláticos de uso veterinário ou agrícola." 7 "Nesse mesmo período veio o Regulamento de Saúde Pública (Dec. 16.300 de 31.12.23) e uma legislação mais específica destinada à proteção do meio ambiente, a partir de 1924, tal como o Código Florestal (Dec. 23.793/34) substituído pelo vigente, instituído pela Lei 4.771 de 15.09 .65 ; o Código de Águas (Dec. 24.643 de 10.07.34) ainda em vigor, que, no Título IV do livro II, sobre águas nocivas, reprime a poluição das águas; o Código da Pesca (Dec.-lei 794 de 19.10.38) trouxe algumas normas protetoras de águas piscosas (arts. $15 \mathrm{~h}$ e 16) que foram ampliadas no Código de Pesca em vigor (Dec.-lei 221, de 28.02.67, arts. 36 a 38). Mas nesses diplomas legais e tutela jurídica do meio ambiente aparecia circunstancialmente. Só recentemente é que se tomou consciência da degenerescência do meio ambiente natural, cuja proteção passou a ser objeto de uma política deliberada, mediante normas diretamente destinadas a prevenir e a recompor a sua qualidade. A União e os Estados editavam leis visando a preservação da qualidade do meio ambiente."8

A nível federal a década de 30 é o marco inicial da atuação mais decisiva na proteção ambiental com a promulgação do Dec. 24.645 de 10.07 .34 estabelecendo medidas de proteção aos animais o Dec. 1.713 de 16.06.37 criando o Parque Nacional de Itatiaia, o Dec.-lei 25 de 30.11 .37 organizando a proteção do Patrimônio Histórico e Artístico Nacional, o Dec. 1.035 de 10.01 .39 criando o Parque Nacional de Iguaçu e o Dec.-lei 1.822 de 30.11 .39 criando o Parque Nacional da Serra dos Órgãos.

"Os anos 40 e 50, principalmente este último, pode ser considerado o período em que surgiram problemas críticos de contaminação do ar e das águas em vários locais do estado de São Paulo, tendo sido desencadeados vários mecanismos de controle desses problemas, entre outros, a Norma Sanitária para o estado de São Paulo, a proibição do lançamento de resíduos que prejudicassem a 
qualidade dos cursos d'água e também a criação do Conselho Estadual de Controle de Poluição das Águas. "A nível federal, as ações se concentraram basicamente na criação de áreas florestais protegidas até 1964 , conforme inúmeros decretos que constam no Código Florestal e os Parques Nacionais de Araripe-Apodi, Ubajara, Jaíba, Aparados da Serra e Araguais e de significativo, embora não consistente, a Convenção para a Proteção da Flora, da Fauna e das Belezas Cênicas Naturais dos Países da América."

Em 1964, através de Lei 4.504 foi instituído o Estatuto da Terra, contendo uma série de artigos relativos à proteção dos recursos naturais.

Ainda a nível federal, entre 1965 e 1969, foram produzidos o Código Florestal, Lei 4.771, o Código de Caça, Lei 5.197, o Código de Mineração, Dec.-lei 227, com o objetivo básico de revisão aos diferentes códigos até então existentes. Com o Dec. 289 de 22.02.67 cria-se o IBDF (Instituto Brasileiro de Desenvolvimento Florestal) e com a Lei 5.318 de 26.09.67 é instituída a Política Nacional de Saneamento criando o Conselho Nacional de Saneamento.

A título de ilustração é interessante notar o "influxo preceptivo ou programático que os princípios internacionais exercem sobre as ordenaçōes estatais, constituindo um válido incitamento à atualização das legislaçōes internas"10. "Nelas é admirável, antes de mais nada, a real compreensão dos problemas, cuja verdadeira proteção só será possível se prescindir dos termos acanhados, peculiares a cada legislação estatal. Estamos nos referindo à década de 70 , quando os efeitos do desenvolvimento se fizerem sentir mais fortemente e mais especificamente à Declaração da Conferência das Nações Unidas sobre o Ambiente Humano, levada à efeito em Estocolmo, de 5 a 16 de junho de 1972."11

Como efeito, é nesse período que se iniciam os esforços para uma política ambiental mais abrangente no Brasil. Segundo o arq. Kazuo, procedeu-se em 1972, a um levantamento entre os nove ministérios e uma Secretaria de Estado, de pelo menos 34 organismos públicos que mantinham implicações diretas ou indiretas com assuntos ambientais. Diante de tal dispersão, alguns passos foram dados, culminando com medidas institucionais básicas.

A primeira foi a criação, no ano seguinte, da SUPREM - Superintendência dos Recursos Naturais, cujo objetivo, entre outros, era de tratar dos recursos naturais como um todo, o que era impossível de se atingir diante da multiplicidade de órgãos existentes.

Em 30.10.73, o governo federal expediu o Dec. 73.030 criando, no âmbito do Ministério do Interior, a Secretaria Especial do Meio Ambiente SEMA, orien- 
tada para a conservação do meio ambiente e o uso racional dos recursos naturais junto à qual funcionará um Conselho Consultivo do Meio Ambiente.

Na década de 80 temos a criação da Lei 6.902 de 27.04 .81 que dispōe sobre a criação de Estações Ecológicas, Áreas de Proteção Ambiental - APAs, e a Lei 6.938 de 31.08 .81 que dispõe sobre a política nacional do Meio Ambiente, seus fins e mecanismos de formulação e aplicação.

Mais especificamente são essas duas leis e mais o Dec. 88.351 de 01.06 .83 que regulamentam as duas leis anteriores, que mais nos interessam no desenvolvimento no trabalho e que no decorrer do mesmo serão discutidas.

Finalmente, o Dec. 9.145 de 1985, cria o Ministério do Desenvolvimento Urbano e Meio Ambiente, com competência para atuar nas áreas de política habitacional, política de Saneamento Básico, política de Desenvolvimento Urbano e Meio Ambiente.

No estado de São Paulo, desde 1951, vem-se editando leis e decretos para o controle e repressão das atividades poluidoras do meio ambiente, tais como o Código Sanitário Estadual (Lei 1.561 A) referindo-se expressamente a poluição do ar. Nesses últimos anos, o Estado procurou sistematizar sua política de proteção ambiental. E, em 1970 cria a Superintendência de Saneamento Ambiental SUSAM (Dec. 52.531) que, além de exercer o controle da poluição atmosférica, visava, também exercer o controle e a erradicação de endemias.

Depois no campo inicialmente apenas da poluição das águas, o Estado criou duas entidades, a Companhia de Saneamento Básico do Estado de São Paulo SABESP (Lei 119) com objetivo de planejar, executar e operar os serviços públicos de saneamento básico em todo o território do estado, respeitada a autonomia dos municípios e a Companhia Estadual de Tecnologia de Saneamento Básico e de Controle da Poluição das Águas CETESB (Lei 118) a quem incumbiu o exercício do controle da poluição das águas em todo o território estadual. Pelo Dec. 5.992 foram transferidas para a CETESB as atribuiçōes e competências sobre a poluição do ar que competia à SUSAM. O Dec. 5.993 alterou a denominação e as atribuições da CETESB, que passou a chamar-se Companhia Estadual de Tecnologia de Saneamento Básico e de Defesa do Meio Ambiente. à qual ficou atribuído o exercício do controle da qualidade do meio ambiente - água, ar e solo, em todo o território do estado de São Paulo, assim como as funções de pesquisas e serviços científicos e tecnológicos direta e indiretamente relacionados com o seu campo de atuação. $O$ Dec. 6.371 dispondo sobre a integração das atividades de proteção do meio ambiente subordinou à manifes- 
tação prévia da CETESB o exame de projetos de loteamento e arruamento por parte da Secretaria da Saúde, quanto aos aspectos de sua competência.

Finalmente em 1983 é criado o CONSEMA Conselho Estadual do Meio Ambiente, com a atribuição de propor e acompanhar a política do meio ambiente no estado de São Paulo, propor normas e padrōes estaduais de controle e manutenção da qualidade ambiental, estabelecer diretrizes para a defesa dos recursos naturais, propor e coordenar a implantação das áreas de preservação ambiental, apoiar a pesquisa e as atividades de educação, documentação e divulgação em assuntos de meio ambiente. Em 1986, o Conselho é transformado em Secretaria Extraordinária do Meio Ambiente.

Fica claro, nesse breve relato, que o objetivo não é analisar de forma detalhada a atuação do poder público na questão ambiental, mas subsidiar uma visão abrangente dessa questão.

\section{AS ÁREAS DE PROTEÇĀO AMBIENTAL E O TOMBAMENTO Entrevista com o arquiteto Kazuo Sakurai}

Durante entrevista realizada com o arquiteto tornou-se evidente a necessidade de uma recomposição histórica da atuação do poder público, do judiciário e de suas competências.

De acordo com o arq. Kazuo, e também por verificações posteriores, o poder público, aqui representado pela União, sempre que tiver interesse em determinada área, quer por conveniência quer por necessidade (embasada em estudos) tem a possibilidade de declarar o local como de "utilidade pública" ou de "interesse social" Feito isso, tem-se a instauração de alguns instrumentos específicos de preservação: a "desapropriação" e a "servidão administrativa" Consideramos, por motivos que posteriormente serão explicados, que o tombamento e as APAs encontram-se no segundo caso.

Para o arquiteto, o tombamento e a APA significam a mesma coisa. Concordamos em parte com essa afirmação. Na teoria são conceitos adversos com significados e conseqüentes conformações espaciais distintas. Talvez na prática é que os dois se assemelhem, pois os limites de intervenção de cada um deles levem à sobreposição de cargos comprometendo dessa forma, a sua funcionalidade.

Cabe aqui um parênteses: como definir um conceito tão elástico como "utilidade pública" e interesse social?

A existência in concreto da utilidade pública e não apenas a simples referência a uma das hipóteses legais descritas pelo Dec.lei 3.365/41 é inarredável para a validade do ato declaratório. 
É dizer, na linguagem de Bielsa: "com efeito: primeiro a causa da utilidade pública é um limite que se impõe ao Estado em defesa da propriedade privada, ou seja, se não há causa de utilidade pública, o Estado não pode expropriar. E comprovar se há causa jurídica também é de causa judicial" 12

Deve-se, pois, procurar se há planos urbanísticos anteriores respaldando o ato declaratório da utilidade pública. Só assim se poderia pretender a realidade jurídica da própria declaração de utilidade pública. "À administração pública é dado optar, sem dúvida, entre uma ou mais situações convenientes ao interesse público. Entretanto, não lhe é dado decidir, sem nenhum limite ou comporta, sobre a utilidade pública (cujo conceito nada mais é do que a própria noção de interesse público. albergada no sistema). Qualquer interpretação só deverá ser feita à luz dos vetores do próprio sistema. Há necessidade insofismável de que a declaração de utilidade pública mantenha estreita compatibilidade com as disposições urbanísticas vigentes tais como: planos diretores gerais, especiais ou prioritários.

Quanto à "servidão administrativa" temos. de acordo com Adilson de Abreu Dalari que "as servidões administrativas podem recair sobre bens móveis e imóveis, tanto públicos como privados e ainda sobre serviços. Basta que algo seja sucetível de apropriação e tenha utilidade prática para que essa utilidade possa ser parcialmente absorvida pelo Poder Público, sem extinguir a propriedade privada. mediante a constituição de uma servidão administrativa ${ }^{13}$.

Em síntese temos que a preservação do patrimônio histórico, cultural, artístico e paisagístico incumbe ao poder público, constituindo-se a norma do art. 180, parágrafo único, do atual texto constitucional em autêntica norma programática.

Entretanto, se, ao tombar determinado bem, o poder público impedir sua utilização, mercê de características especiais desse bem. deverá expropriá-lo. Se limitar a utilização onerando destarte, o particular, por se constituir em autêntica servidão administrativa deverá indenizá-lo.

E finalmente as servidões administrativas podem constituir-se sobre quaisquer bens, móveis ou imóveis e devem ser indenizadas, na medida do ônus ocasionado ao particular ${ }^{14}$

Pode-se dizer que é nesse ponto que se inicia a parte principal do trabalho referente às áreas designadas de interesse público passíveis de desapropriação ou, em nosso caso mais especificamente de servidão administrativa não indenizada pelo Estado fundamentada no primeiro caso APA Corumba taí/Botucatu/Tejupá. em 
estudos e pesquisas e no segundo caso APA Cajamar/Cabreúva/Jundiaí baseado em "conveniências políticas" e interesses obscuros.

A palavra TOMBAMENTO significa arrolamento, inventário, registro, etc. Neste sentido é o reconhecimento formal, pelo poder público, do valor cultural de um bem: uma construção, um objeto, um bairro, uma cidade, uma paisagem, etc. A finalidade de tombamento é a proteção e a conservação, impondo a valorização dos monumentos ou bens de valor cultural, artístico e natural, em seus diversos níveis.

Para que um bem cultural integre o patrimônio histórico, artístico e natural do país, terá que estar inscrito separado, ou agrupadamente, num dos quatro livros do Tombo, que são:

\section{a) Livro do Tombo Histórico \\ b) Livro do Tombo das Artes Aplicadas}

c) Livro do Tombo Arqueológico, Etnográfico e Paisagístico onde se inscrevem as coisas de arte arqueológicas, ameríndia e popular, bem como os monumentos naturais, os sítios e paisagens de feição notável, tanto pela natureza como pela indústria humana.

Tendo sido lançado nos livros do Tombo, o bem passa então, a desfrutar da proteção (ao menos teórica) do estado, em todos os níveis administrativos, que por ele deve zelar. Reconhecido o interesse público nesse bem, a agressão e ele constitui crime contra o patrimônio nacional. Apesar da coerência desta idéia já legalmente formulada, é de conhecimento geral a inépcia com que o poder público trata desses bens, não se tendo conhecimento de que tenha sido alguém condenado por ferir o patrimônio nacional nesses termos." 15

\section{CONSIDERAÇŌES LEGAIS - A APA CORUMBATAÍ / BOTUCATU/ TEJUPÁ}

As Áreas de Proteção Ambiental APAs, são criadas com base na lei federal 6.902 de 27.04.81 que dispōe sobre a criação de Estaçōes ecológicas e áreas de Proteção Ambiental que em seu artigo 8ำ estabelece:

"O poder executivo, quando houver relevante interesse público poderá declarar determinadas áreas do território nacional como de interesse para a proteção 
ambiental, a fim de assegurar o bem-estar das populações humanas a conservar ou melhorar as condições ecológicas locais.

Artigo 90:

"Em cada área de proteção ambiental, dentro dos princípios constitucionais que regem o exercício do direito de propriedade, o poder executivo estabelecerá normas limitando ou proibindo:

a) A implantação e o funcionamento de indústrias potencialmente poluidoras, capazes de afetar mananciais de água.

b) A realização de obras de terraplenagem e a abertura de canais quando essas iniciativas importarem em sensível alteração das condições ecológicas locais.

c) O exercício de atividades capazes de provocar uma acelerada erosão das terras e/ou acentuado assoreamento das coleções hídricas.

d) O exercício da atividade que ameace extinguir na área protegida as espécies raras da biota regional."

Logo depois, pela lei federal 6.938 de 31.08 .81 , as áreas de proteção ambiental foram incluídas entre os instrumentos da Política Nacional de Meio Ambiente.

Através do Decreto-lei 88.351 de 01.06 .83 as duas leis anteriores são regulamentadas, dispondo 0 artigo 32:

"O decreto que declara a Área de Proteção Ambiental mencionará a sua denominação, limites geográficos, principais objetivos e as proibições e restrições de uso dos recursos ambientais nela contidos."

"Várias dúvidas podem surgir da leitura desses textos legais, pois, se o art. $9^{\circ}$ da Lei 6.902/81 já definiu o campo de abrangência das restrições a serem feitas, ou seja, sobre quais as atividades incidirão as limitações e proibições, é de se indagar se poderão ser restringidas a outras atividades poluidoras (que não atividades industriais) e que poluam o ar e solo (a remoção da cobertura vegetal, a exploração de jazidas, etc.). Acresce que o elenco descrito no citado art. 9o não é preciso, pois deixa margem à discussão ao referir-se à sensível alteração, acelerada erosão ou acentuado assoreamento.

De qualquer forma, parece que tal elenco não é meramente exemplificado, o que torna extremamente restrito o campo de abrangência de uma área de proteção ambiental, dificultando o pleno atingimento dos fins colimados: "assegurar o bem-estar das populações e conservar e melhorar as condições ecológicas locais" 
Por sua vez, a tipificação das infrações cometidas em Áreas de Proteção Ambiental é também bastante restrita, não possibilitando a punição de inúmeros comportamentos indesejáveis em tais unidades de conservação.

A Lei 6.902/81 estabeleceu, em seu artigo $9^{\circ}, \S 2$ que o não cumprimento das normas ali estabelecidas sujeitará os infratores ao embargo das iniciativas irregulares, à medida cautelar de apreensão do material e das máquinas usadas nessas atividades e à obrigação de recomposição e reconstituição, tanto quanto possível, da situação anterior e à imposição de multas.

Ocorre que a Lei 6.902/81 foi regulamentada, juntamente com a lei 6.938/81, pelo Decreto 88.351 de 01.06 .83 que, além de conter dispositivos específicos sobre APAs, tipificou os comportamentos infratores e estabeleceu as respectivas penalidades. Porém, em momento algum referiu-se às multas, previu-se sua imposição nos já descritos incisos VII e VIII do artigo 37 e em artigo 38, que reza:

"Serão impostas multas de 50 a 100 OTNs, proporcionalmente à degradação ambiental causada, nas seguintes infrações:

1. Realizar em Área de Proteção Ambiental, sem licença do respectivo órgão de controle ambiental, abertura de canais ou obras de terraplenagem, com movimentação de areia, terra ou material rochoso. em volume superior a $100 \mathrm{~m}^{3}$, que possam causar degradação ambiental.

Tal elenco de infrações e penalidades dificulta a punição de comportamentos indesejáveis não relacionados. Acresce que somente foram mencionadas as atividades expressamente previstas no art. 9 da Lei 6.902/81 o que, mais uma vez, leva ao entendimento de que somente aquelas atividades podem ser restringidas. Por outro lado, o artigo 38 se refere a uma licença não constante dos dispositivos pertinentes às APAs e a um fator condicionante (volume superior a $100 \mathrm{~m}^{3}$ ) também até então inexistentes.

Examinando os decretos federais que criaram Áreas de Proteção Ambiental, verificamos que não se limitam às proibições elencadas na Lei 6.902/81, ampliando $o$ grau de restrições administrativas nela previstas, tendo em vista os objetivos fixados, incluindo o controle sobre outras fontes de degradação ambiental, projetos de urbanização. construção de quaisquer edificações, proibição de uso biocidas capazes de causar mortandade de animais vertebrados.

Os referidos decretos prevêem ainda que na implantação e funcionamento da Área de Proteção Ambiental se proceda a seu zoneamento, através da Portaria da SEMA. 
É de se observar que, quanto à eficácia, os decretos federais que criaram APAs apresentam melhores condições de execução do que aqueles editados por alguns estados membros como ocorre no estado de São Paulo.

Examinando a legislação paulista, por exemplo, verifica-se que as leis e decretos que criaram APAs estabeleceram que "na implantação da APA serão aplicadas medidas previstas na legislação e poderão ser celebrados convênios visando evitar ou impedir o exercício de atividades causadoras de degradação da qualidade ambiental" Previram também que tais medidas procurarão impedir os mesmos comportamentos elencados no artigo $9^{0}$ da Lei 6.902/81, incluindo apenas as atividades potencialmente poluidoras, capazes de afetar mananciais de água, solo e ar.

Coloca-se aí a questão da implantação das APAs, já que se trata de evento a se verificar no futuro, sob a coordenação do Conselho Estadual de Meio Ambiente. a quem cabe também a sua administração. As leis e decretos paulistas, da forma em que estão redigidos, indicam que as restrições de uso do solo e dos recursos naturais somente se farão efetivas a partir desse momento, porém, não definem "como" e "quando" se dará essa implantação e de que forma serão definidas as medidas a serem adotadas naquelas unidades de conservação. Tal indefinição tem dificultado sobremaneira a administração das APAs no estado de São Paulo, inclusive no que se refere à fiscalização das atividades ali desenvolvidas, já que também a entidade fiscalizadora e as penalidades não foram definidas na legislação estadual ${ }^{16}$.

\section{QUANTO AOS OBJETIVOS DE PRESERVAÇĀO - APA CORUMBATAÍ / BOTUCATU / TEJUPÁ}

No caso do Decreto estadual 20.960 de 08.07 .83 que cria a APA Corumbataí/Botucatu/Tejupá, os principais objetivos da preservação são, pode-se dizer, apesar de específicos para aquela região, ainda muito genéricos e incompletos. Tais falhas relacionavam-se quanto à indefinição de "como" e "quando" seriam implantadas algumas propostas (fiscalização, urbanização...). Para resolver tal problema. a CETESB decidiu complementar os estudos que haviam sido realizados quando da declaração da APA em 1893, e com isso, em julho de 1986 regulamentou. em forma de lei. as suas propostas e diretrizes de atuação.

Isso foi feito levando em conta que as várias atividades consideradas inadequadas e indesejáveis continuam sendo instaladas nessa APA, alegando a não regulamentação das propostas de 1983 e se servindo da interpretação de uma legislação falha e repleta de lacunas. 
Ainda hoje, apesar de regulamentada, é possível a instalação de qualquer atividades, pois sempre que possível se utilizam da legislação genérica que cria as APAs (1981), ou ainda se valem da sobreposição e contradição dos instrumentos que compõem a Política do Meio Ambiente.

No caso específico da APA Corumbataí/Botucatu/Tejupá, a CETESB, responsável pelos estudos técnicos realizados na área, complementou e especificou os relatórios de forma clara e precisa. Para que nenhuma outra atividade. considerada prejudicial ao meio e que não esteja dentro daquelas já previstas, fosse ali instalada ou desenvolvida, a CETESB realizou uma proposta de regulamentação da área em julho de 1986. Na entrevista ficou claro que esta será a política adotada pela companhia. Pelo que foi dito, todas as preposições presentes no relatório foram concretizadas e os relatórios foram regulamentados.

\section{QUANTO AOS OBJETIVOS DE PRESERVAÇÃO APA CAJAMAR / JUNDIAÍ / CABREÚVA}

Na realidade, não foi possível realizarmos os estudos da APA Cabreúva, foco de estudo de nossa dissertação, porque absolutamente NADA foi realizado até o presente momento sobre aquele lugar; o porquê disso será explicado no decorrer do trabalho. Embora os três municípios integrassem apenas uma APA. e tivessem sido aprovados como projeto de lei na mesma época e pelo deputado estadual Randal Juliano Garcia (14.09.83) na Assembléia Legislativa e pelo governador do estado de São Paulo (04.06.84). elas serão tratadas separadamente. pois os pedidos de inserção numa APA foram pedidos separadamente e seus estudos também.

Não nos foi possível chegar à justificativa do projeto de lei que criou a APA Cabreúva, embora a Assembléia Legislativa esteja "teoricamente aberta" ao cidadão para o esclarecimento de qualquer dúvida: para nós, isso levaria de 4 a 5 meses. Portanto. devido à generalidade do texto e por depoimentos de técnicos da CETESB, consideramos que o então deputado estadual Randal Juliano Garcia tenha utilizado do mesmo artifício para as três APAs e sua aprovação. Quanto aos motivos de criação, estes foram os mesmos: redutos eleitorais e conveniências políticas (essas declarações, embora tenham sido obtidas "extraoficialmente" são facilmente comprováveis nos estudos e pesquisas realizadas pela CETESB).

A primeira dúvida que se apresenta é por que só agora o município de Cajamar é estudado e os outros dois nāo o são? 
Também por problemas que só agora surgiram com o desenvolvimento do novo Plano Diretor de Mineração da região metropolitana de São Paulo que previa a instalação de várias atividades de extração mineral na área, uma das principais fontes de renda do município, ficou patente a necessidade de revisão da proposta de declaração de Área de Proteção Ambiental de toda a região do município, que impedia a implantação de qualquer tipo de atividades mineradoras da área e prejudicava o funcionamento das já instaladas.

Se na APA Corumbataí/Botucatu/Tejupá, criada por decreto federal embasada em estudos prévios da área, já ocorriam problemas de todos os tipos. com a declaração da APA Cajamar/Jundiaí/Cabreúva, sem estudos prévios e com uma justificativa genérica e incorreta, baseada numa legislação lacunosa, e em interesses que não nos cabe aqui discutir, só poderiam criar problemas ainda mais graves. O mais interessante é que o próprio órgão responsável pela transformação em lei deste projeto a CONSEMA. é agora a responsável pelos pedidos de estudos que pretendem, se não revogar a lei, pelos menos limitar a atuação da APA.

A justificativa que passou pela assembléia e pelo CONSEMA com aprovação da CETESB (que na época era uma secretaria ligada ao CONSEMA) é esta:

"A paisagem de Cajamar é marcada pela interferência do homem; porém não se detecta, a princípio, graves problemas ambientais que possam por em risco a saúde da população (justificativa para criação da APA). Nem mesmo a área abrangida pelas Serras do Japi. Guaxinduva e Jaguacoara, tombada pela Secretaria da Cultura conforme Res. $n^{\circ}$ II de 08.03 .83 , justificativa para a criação da APA, se acha localizada no município. Entretanto a médio e longo prazos, a situação pode se alterar, caso não sejam tomadas medidas preventivas em relação aos processos ou atividades que possam provocar impactos ambientais." 17

Por solicitação do CONSEMA Conselho Estadual do Meio Ambiente, órgão responsável pela coordenação da implantação dessa APA, os trabalhos técnicos dessa etapa, correspondentes ao Diagnóstico da Área de Proteção Ambiental de Cajamar/Jundiaí/Cabreúva, foram desenvolvidos.

De acordo com o arq. Kazuo, pelo menos na área ambiental, era normal que se regulamentassem quaisquer projetos de lei desde que passassem pela Assembléia: como isso acontece movido por "jogos políticos" e não pela razão. Assim, algumas APAs foram decretadas de forma imprecisa e a sua revogação ou correção se o diagnóstico e sua regulamentação forem pedidos: para tanto é preciso que haja algum interesse público, ou quem sabe, que algum projeto tenha sido prejudicado pela declaração de APA. 
Quanto ao município em estudo, Cabreúva - a APA não tem grande significado, pois atividades tidas como predatórias (incêndios seguidos da instalação de loteamentos em áreas tombadas pelo CONDEPHAAT, atividades mineradoras e industriais, entre outros) são fatos corriqueiros.

\section{CRÍTICAS À ELABORAÇĀO DO TEXTO DA RESOLUÇĀO DE № 11 DE 08.03.83}

No seu artigo $3^{\circ}$ o CONDEPHAAT apresenta condiçōes de uso para pequenos produtores agrícolas só que não especifica em nenhum momento quais são. No $\S 3$, os mineradores tradicionais (lavra do solo) podem continuar trabalhando e as mineradoras que iniciarem seus trabalhos poderão entrar em acordo com o DNPM e o CONDEPHAAT, através de um grupo de trabalho a ser organizado (ninguém sabe quando). Depois disso deverá passar pelo CONSEMA o mesmo que aprovou a Área de Proteção Ambiental de Cajamar e agora tenta revogá-la.

No $\S 5$ sugere-se o desmatamento de matas secundárias para construção de residências e anexos em áreas consideradas como sítios de lazer: pelo menos. inicia-se os índices de desmatamento e sugere-se as matas secundárias. E quem fiscaliza a derrubada da mata considerada "secundária" pelo proprietário?

No § 14, do mesmo artigo, sugere-se a implantação de parques estaduais e municipais de área restrita e a implantação de um sistema de acervos. Perguntase: como, quando e por quem?

No § 17, diz-se que não é permitida a instalação industrial, carvoaria e madeira dentro do perímetro da área de tombamento. Sugerimos, então, que o Estado, responsável por essas áreas, através de seus representantes, faça um "passeio" até os municípios atingidos pelo tombamento e faça as suas averiguações.

No artigo $4^{0}$ "fica prevista a criação de uma comissão interórgãos públicos, para controle de organização do espaço, ordenação dos acessos e previsão periódica da situação efetiva da preservação da natureza, na região da Serra do Japi" Não é necessário entrarmos em maiores detalhes quanto à análise do artigo, pois é, infelizmente, evidente, que absolutamente nada disso foi efetuado.

O problema mais grave, em nosso ponto de vista, encontra-se na forma em que foi definida a área de tombamento: seguiu uma simples curva de nível, o que a nosso ver, não significa nada muito preciso ou delimita o espaço. 


\section{ALGUMAS CONSIDERAÇÕES}

No decorrer do trabalho ficou claro que possuímos, bem ou mal, instrumentos capazes de deter a ação predatória do homem, embora já pudéssemos ter evoluído mais. "No entanto, esse fato não deve servir de entrave ao desenvolvimento de uma mentalidade preservacionista atenta às mudanças sociais, as quais influem diretamente na elaboração do direito. Evidentemente há os extremismos e os excessos como também as resistências, o que ocorre em todas as mudanças sociais. Por esse motivo, hoje mais do que nunca é exigida a presença do poder público na defesa da conservação e preservação dos recursos naturais, com objetivo econômico, pouco se importam com o futuro. Estão mais preocupados com a maximização dos seus lucros. Por esta razão cabe ao poder público, que representa o interesse coletivo, zelar para que os recursos naturais não sejam dilapidados irracionalmente.

Ao se pensar na responsabilidade do Estado por danos decorrentes por sua omissão no exercício do poder de polícia, vimos que em nosso sistema jurídico é possível exigir-se uma reparação pecuniária. Entretanto, em termos de conservação e preservação dos recursos naturais e do meio ambiente, essa reparação não é tudo, pois quando ocorre já houve a violação, muitas vezes irreparável. Por isso, é necessário que ao lado da reparação patrimonial haja também uma reparação com a sociedade. $O$ indivíduo que atenta contra o meio ambiente depredando os recursos naturais de forma irracional, além do dano material que causa é anti-social. Merece, por esse motivo, uma punição pessoal. Desta forma, esse tipo de dano, além de ofender o patrimônio material, ofende também a sociedade. É um ilícito penal, independente do civil. Em nossas leis, temos uma infinidade de dispositivos penais, mas que infelizmente não inócuos. Talvez o mau funcionamento da Justiça contribua para isso. Vemos constantemente depredações criminosas de florestas, atentados contra a saúde do povo por intermédio de materiais poluentes lançado às águas, à atmosfera e aos alimentos" 18

Apenas a título de curiosidade, é interessante notar como a especulação imobiliária e a legislação "evasiva" andam "de mãos dadas": no município de Cabreúva temos uma Serra tombada pelo CONDEPHAAT, e que já foi incendiada pelo menos três vezes no ano passado, o que nos levaria a supor que seria coincidência. Acontece, porém, que ficou "comprovado" pelo CONDEPHAAT que o acontecimento não era criminoso, pois por duas vezes havia sido ocasionado por crianças que brincavam de fogueira no pé da serra e a outra havia sido ocasionada por uma ponta de cigarro. No caso, o Estado. ou o órgão responsável deveriam ter estudado a possibilidade de evitar esse tipo de acontecimento e tentar a recomposição, se possível, da flora original. O que 
aconteceu, porém, é que alguns dias depois, iniciou-se no local um stand de vendas imobiliárias anunciando a venda de lotes para residência. tendo como chamariz algo que não mais existia: a "exuberante" floresta que compõe a Serra do Japi.

\section{NOTAS}

(1) COSTA Jr., Paulo José da. et al. Direito Penal Ecológico.

(2) Idem ao anterior.

(3) Idem ao anterior.

(4) Idem ao anterior.

(5) Sakurai.. Kazuo Depoimentos e textos particulares, abr./87.

(6) Idem ao anterior.

(7) Idem ao anterior.

(8) SILVA, José Afonso da. Aspectos jurídicos do patrimônio ambiental.

(9) CESP, Legislaçāo de Conservaçāo da Natureza.

(10) COSTA JR., Paulo José da. et. al. Direito penal ecológico.

(11) Idem ao anterior.

(12) FIGUEIREDO, Lucia Valle. Disciplina urbanistica da propriedade.

(13) Idem ao anterior.

(14) Idem ao anterior.

(15) CENEVIVA, Laura L. Vieira, et al. Instrumentos de preseriaçāo.

(16) CETESB. Área de Proteçāo Ambiental, CorumbataílBotucatu/Tejupá.

(17) CETESB, Diagnóstico da Área de Proteçāo Ambiental de Cajamar.

(18) MAGALHÃES, Juraci Perez. Recursos Naturais, Meio Ambiente e sua Defesa no Direito Brasileiro.

\section{BIBLIOGRAFIA}

Anotações de aula Curso de Atualização "Patrimônio e Recursos Naturais" realizado entre março e junho de 1986 pelos professores: José Pereira de Queiroz Neto e Miranda M. Magnoli, na FAUUSP.

CENEVIVA, Laura L. Vieira et al. Instrumentos de preserr açāo. Trabalho realizado para o curso de especialização em Patrimônio Cultural, São Paulo: FUPAM, 1986.

CESP. Legislaçāo de conservaçāo da natureza. 3o ed., revista e atualizada até 20.09.82, São Paulo: 5, CESP. 1983.

CETESB/ACETESB. Legislaçāo: controle da poluiçāo ambiental. São Paulo: CETESB, 1986. 
Legislaçāo Federal: controle da poluiçāo ambiental. São Paulo: CETESB, 1986.

CETESB. Área de proteçāo ambiental, Corumbataí/Botucatu/Tejupá, proposta de regulamentaçāo. São Paulo: CETESB, 1986.

. Diagnóstico da área de proteçāo ambiental de Cajamar. São Paulo: CETESB, 1986.

SEMINÁRIo SObre polftica naCiOnal do MeIO ambiente. São Paulo, Cesteb, 1985.

COIMBRA, José de Ávila Aguiar. O outro lado do meio ambiente. São Paulo: CETESB, 1981.

FIGUEIREDO, Lúcia Valle. Disciplina urbanística da propriedade. São Paulo: Ed. Revista dos Tribunais, 1980.

IUCN, Estratégia mundial para a conservaçāo dos recursos vivos para um desenvolvimento sustentado. São Paulo: CESP, 1984.

MAGALHÃES, Juraci Perez. Recursos naturais, meio ambiente e sua defesa no direito brasileiro. Rio de Janeiro: Fundação Getúlio Vargas, 1982.

MEIRELES, Helí Lopes. Direito municipal brasileiro, 5 a ed. atualizada. São Paulo: Ed. Revista dos Tribunais, 1985.

MOURA, Ana M. Silva de et al. $O$ espaço aberto produzido e o seu lugar como patrimônio cultural. São Paulo: FUPAM, 1986.

RESOLUÇÃO n 11 de 08 de março de 1983.

SILVA, José Afonso da. Aspectos jurídicos do patrimônio ambiental. São Paulo: 1981. . Direito urbanístico brasileiro. São Paulo: Ed. Revista dos Tribunais, 1981.

Texto originalmente publicado no Paisagem e Ambiente - Ensaios II.

(*) Arquiteta, mestre e doutoranda FAUUSP, professora de Paisagismo da UNIP-SP e FAU-Braz Cubas (Mogi das Cruzes-SP), pesquisadora do Grupo de Disciplinas Paisagem e Ambiente do Departamento de Projeto. 